\title{
O ENTÃO EM DEBATES ORAIS: UM ESTUDO FUNCIONALISTA ${ }^{\mathrm{I}}$
}

\author{
Mateus Rodrigues de Moura \\ Graduado em Letras pelo Instituto Federal de São Paulo (IFSP) \\ teu.moura10@gmail.com \\ Cristina Lopomo Defendi \\ Doutora em Filologia e Língua Portuguesa pela Universidade de São Paulo (USP) \\ Professora do Instituto Federal de São Paulo (IFSP) \\ crislopomo@gmail.com
}

\section{RESUMO}

Neste artigo, descrevemos o "então" como estrutura linguística típica de argumentação do Português oral do Brasil e apresentamos, como metodologia, a análise qualitativa a partir de dados coletados de um corpus composto por debates orais disponíveis nos canais do Youtube. Como resultado, após mapeamento das funcionalidades deste elemento linguístico em textos orais, constatamos dois usos característicos: ora como um operador argumentativo conclusivo - em que há classes argumentativas distintas, mas uma única orientação de argumentação e ora como um marcador conversacional - iniciador de turno anafórico.

Palavras-chave: gramaticalização, argumentativos. funcionalismo, operadores

\section{ABSTRACT}

In this article, we describe the "then" as a typical linguistic structure of oral Portuguese argumentation in Brazil and we present as methodology, the qualitative analysis of data collected from a corpus composed of oral debates available on YouTube channels. As a result, after mapping the functionalities of this linguistic element in oral texts, we found two characteristic uses: either as a conclusive argumentative operator - in which there are distinct argumentative classes, with a single orientation of argumentation or as a conversational marker - a speech initiator with anaphoric function.

\section{Keywords:}

functionalism, grammaticalization, argumentative operators. 


\section{Introdução}

Muito se tem pesquisado acerca de itens linguísticos que desempenham funções argumentativas, inclusive sobre o item então. Este, por sua vez, pode ser analisado com diversas funções gramaticais, tais como as desempenhadas por advérbio, conectivo ou operador argumentativo. Porém, grande parte de tais pesquisas refere-se a textos escritos e, poucas vezes, a falas individuais de entrevistados e interlocutores de diversas variações e modalidades linguísticas do Português do Brasil (MARTELOTTA; VOTRE; CEZÁRIO, 1996; CHIARELLI, 2011). Tendo isso em vista, o diferencial desta investigação se dá pelo gênero escolhido, para análise, o debate regrado, modalidade discursiva marcadamente argumentativa e ainda com muito potencial para ser explorada no âmbito acadêmico.

Para tanto, realizamos um levantamento dos padrões funcionais do então, em um universo de cerca de mais de 28000 palavras, nos turnos enunciativos dos debatedores, visando à preservação da espontaneidade e naturalidade de seu uso em debates orais sobre um tema polêmico: porte de drogas e a possibilidade de descriminalização de tal prática.

Assim, este trabalho tem por objetivos descrever as funcionalidades do elemento então em alguns debates orais/regrados disponíveis no Youtube, bem como analisar a forma como tal item direciona a argumentatividade de um indivíduo frente a contrapontos - argumentos contrários e refutações -, os quais são frequentes em debates regrados/orais.

Como base teórica, amparamo-nos em um estudo pancrônico do então (CHIARELLI, 2011) e em seu aspecto etimológico. Posteriormente, relacionamos ao 
funcionalismo (NEVES, 1994), à gramaticalização de itens e às construções de língua portuguesa do Brasil (MARTELOTTA; VOTRE; CEZÁRIO, 1996).

Na próxima seção, contextualizamos o aparato teórico da pesquisa, conceituando - paradigma de gramaticalização e apresentando a temática de operadores argumentativos e sua importância. Em seguida, a partir dos padrões funcionais do então, analisamos algumas ocorrências. Por fim, discorremos, brevemente, sobre os resultados obtidos com a pesquisa.

\section{Fundamentação teórica}

Os estudos de base funcionalista adotam uma abordagem que considera a língua como um instrumento de interação social (DIK, 1978), a qual possui como primordial finalidade a comunicação, enfatizando seu uso e aspecto funcional. Desse modo, as funções de um determinado sistema linguístico dependem do seu uso e, consequentemente, do contexto em que é utilizado. Seguindo tal linha de raciocínio, temos que "itens linguísticos sofreriam pressão do contexto, o que levaria à mudança linguística, especialmente em favor a um ganho de gramaticalidade" (CHIARELLI, 2011, p. 12).

Posto isso, adotamos o paradigma da gramaticalização, conforme Heine, Claudi e Hünnemeyer (1991), Traugott e Heine (1991) e Hopper e Traugott (1993), como seguimento de mudança semântica unidirecional, segundo o qual um elemento lexical ou uma construção passa a assumir funções gramaticais e formas já gramaticalizadas, com a continuidade do processo, passam a desempenhar novas funções gramaticais 
(MARTELOTTA; VOTRE; CEZÁRIO, 1996). Portanto, a gramaticalização investiga como itens linguísticos tornam-se gramaticais ${ }^{\mathrm{ii}}$.

Martelotta, Votre e Cezário (1996) propõem o seguinte continuum de abstratização funcional que aborda o escopo desta pesquisa - o elemento linguístico então: espaço > (tempo) > texto. Essa rota de mudança serviria para explicar o fato de circunstanciadores espaciais passarem a ser usados, metaforicamente, para estabelecerem relações entre partes do texto, podendo ou não terem sido usados com noção temporal, mais abstratizada em relação à noção espacial. Ao realizarem a articulação textual, passam a ser operadores argumentativos, cuja "função básica é organizar internamente o uso da língua" (MARTELOTTA; VOTRE; CEZÁRIO, 1996, s.p.iii). Os autores afirmam, ainda, que "os operadores argumentativos tendem a ser provenientes de circunstanciadores espaciais e temporais por um processo de gramaticalização, em que ocorre uma passagem do léxico à gramática".

Além desse mecanismo metafórico, há a pressão por informatividade, guiada por mecanismos metonímicos que fazem com que um elemento linguístico, por convencionalização de implicaturas conversacionais, incorpore o valor funcional de elementos informacionais avizinhados, gerando processos de reanálises derivados do contexto de uso. É apresentado o exemplo de embora que, originalmente, assume valor temporal e passa a assumir função concessiva, visto que, em determinados contextos, o sentido de contraexpectativa situacional acaba sendo inferido do tempo em que esse evento fora consubstanciado. Essa incorporação permite afirmar que tempo é categoriafonte para a função de concessividade.

Sobre os operadores argumentativos, ainda conforme os autores, para além do estabelecimento de relações coesivas entre segmentos textuais, tais mecanismos 
argumentativos servem, também, para evidenciar preocupações do falante quanto às expectativas do ouvinte. Ou seja, há uma implicação entre a relação interpessoal (marca de intersubjetividade) e a relação textual. Além disso, é necessário salientar que, tanto em texto escrito como no discurso oral, as ideias são e estão sendo articuladas pelo uso de elementos gramaticais que garantem essa "amarração", a saber, conectivos e operadores argumentativos em geral.

Outro trabalho que reflete essa preocupação com a movimentação funcional de conectivos é o de Neves (2002). Uma ideia bastante presente nesse trabalho é o caráter gradual com que expressões podem vir a se gramaticalizar. Essa postura reforça a acomodação contínua da gramática:

Afinal, a grande importância da consideração do processo de gramaticalização para o estudo linguístico reside na colocação em foco de uma característica básica dos sistemas linguísticos, que é a sua existência e vitalidade exclusivamente em função da sua necessidade para uso dos falantes, daí por que a sua sensibilidade às pressões do funcionamento linguístico, que se temperam com as pressões vindas do próprio amarramento interno do sistema. Nesse constante acerto de equilíbrio é que a gramática - uma estrutura cognitiva ajustável, a partir de núcleos nocionais - vive a acomodação que lhe garante a satisfação das necessidades comunicativas dos usuários (NEVES, 2002, p. 187-188).

Em Andrade (2011), temos uma breve citação sobre o item então em sua pesquisa, o qual é tido como marcador conversacional, o que colaborou para as classificações dos dados do corpus transcrito, visto que, apesar de tal funcionalidade não fazer parte, necessariamente, do conteúdo do discurso, tem grande importância em seu aspecto interacional, pragmático e, por conseguinte, argumentativo. 
A importância de se trabalhar com tais itens linguísticos é "conscientizar o usuário da língua do valor argumentativo dessas marcas, para permitir-lhe percebê-las no discurso do outro e utilizá-las, com eficácia, no seu próprio discurso" (KOCH, 1987, p. 110).

Nesta pesquisa, partimos das seguintes hipóteses já levantadas por Martelotta, Votre e Cezário (1996, s. p.) e, a partir delas, propusemos questões a serem respondidas com a análise do corpus de debates orais (i. O uso do então em corpus de modalidade oral é realmente produtivo? e ii. $\mathrm{O}$ que os debates orais selecionados revelam sobre as estratégias argumentativas dos falantes, em especial com o uso do então?).

a) O elemento então aparece em maior número em textos da modalidade oral, uma vez que além de ser um elemento muito usado na fala, a modalidade escrita conta com um conjunto mais rico de conectivos que podem desempenhar, na escrita, funções semelhantes à do elemento então.

b) A gramaticalização constitui um processo unidirecional de mudança no sentido +concreto > -concreto. Os resultados da gramaticalização tendem, portanto, a ser responsáveis por funções mais abstratas, como a expressão de noções lógicas ou a realização de estratégias comunicativas. É de se esperar que os usos mais gramaticalizados, por constituírem funções mais abstratas, predominem em níveis de escolaridade elevados (MARTELOTTA, VOTRE e CEZARIO, 1996, p. 47).

\section{Metodologia e corpus}

Como procedimentos metodológicos, montamos um corpus com transcrições de seis debates orais - disponíveis no Youtube -, o qual é composto por cerca de 28000 palavras (média estimada), e contabilizamos as ocorrências do então na fala dos debatedores, a fim de analisá-los à luz do funcionalismo e da gramaticalização, e 
caracterizar possíveis funções que tal item desempenha na modalidade oral da língua portuguesa.

A escolha do material para compor o corpus foi motivada por alguns fatores: (i) os debates eram uma forma de discutir um tema emergente à época, um Projeto de Lei (2016) que previa a mudança do Sistema Nacional de Políticas sobre Drogas (Sisnad), ou seja, possui temática única; (ii) os especialistas apresentavam argumentos favoráveis ou contrários à ideia da descriminalização das drogas, muitas vezes tendo que rebater ou reforçar pontos de vistas diversos e, para isso, usavam inúmeros mecanismos linguísticos que organizavam a argumentação; (iii) os debates foram veiculados em programas televisivos de abrangência regional ou nacional, sendo representativos de um uso real e visam à persuasão, com argumentos, do ouvinte/telespectador; e (iv) os falantes são representativos de estratos sociais com níveis de escolaridade mais elevados e papel social relevante - professores, advogados e deputados.

Considerando-se as questões de naturalidade e de espontaneidade do falante em seus argumentos, as quais tornam válidos os dados de amostragem da modalidade oral aqui apresentados, optamos por excluir os turnos enunciativos dos entrevistadores, repórteres e mediadores de tais debates, tendo em vista que estes possuem, em geral, falas ou frases já pré-estabelecidas (e escritas) antes mesmo de os debates iniciarem, tornando as considerações inicialmente citadas - o aspecto espontâneo e natural da fala e o da argumentação - inválidas e não correspondentes ao escopo da presente pesquisa.

A partir dos debates transcritos ${ }^{\text {iv }}$, foi realizado um levantamento de todas as ocorrências do então. Com isso, foi possível realizar uma organização dos dados a partir de padrões funcionais para posterior análise. Todos os dados tiveram, assim, análise qualitativa. 


\section{Definições e etimologia}

No dicionário eletrônico Houaiss de língua portuguesa (2001), então é classificado em três classes gramaticais, a saber, advérbio, interjeição e substantivo. Como advérbio, ele significa "1. nesse ou naquele momento. 2. em tal caso, nessa situação. 3. em momento futuro". Já como interjeição, "4. voz que expressa admiração, espanto. 5. voz que serve para animar"; como, por exemplo, "então, você se cansou?". E, por fim, como um substantivo masculino, que é conceituado como "6. tempo que passou; antanho" (2001); exemplificando: "numa lembrança de então, recordou-se da juventude".

Partimos de tais significações, bem como do princípio de que os usos de então são advindos de uma mudança linguística por gramaticalização espaço > (tempo) > texto. Assim sendo, no Português do Brasil, tal elemento não mais possui sentido espacial, contudo, tal valor pode ser encontrado na composição de origem latina, a saber, a preposição latina "in" mais o advérbio "tunc", que significa algo como "naquele momento; então" (MARTELOTTA; VOTRE; CEZÁRIO, 1996; HOUAISS, 2001).

Prosseguindo com tal justificação da gênese das funcionalidades de então, Martelotta, Votre e Cezário (1996) citam teóricos, como Faria (1975), Leite e Jordão (1958) e Bailly (1950), que abordam certas peculiaridades de tal operador argumentativo. Por exemplo, Faria (1975) apresenta o valor de advérbio de então. Leite e Jordão (1958), por meio da base demonstrativa "tum", aponta tal elemento como originário do grego antigo, isso devido à raiz "te", base presente em elementos de intensificação e dos pronomes. Por fim, consoante Bailly (1950), tal partícula "te" possuía função enclítica, correspondendo tanto a um pronome relativo, "por isso, por essa razão", como a uma conjunção, "e, em outro; em resumo, em fim; com". 
Desse modo, temos que, com tal argumentação,

(...) essa origem demonstrativa (que remete a dados espaciais) do elemento tum e dos demais elementos de intensificação acima mencionados explica o valor anafórico, que estes elementos apresentam até hoje. É desse valor que surgem os atuais valores argumentativos desses elementos: então (conclusivo), portanto (conclusivo), entretanto (adversativo), entre outros (MARTELOTTA; VOTRE; CEZÁRIO, 1996, p. 46).

\section{Análise de dados}

Ao todo, tivemos 116 ocorrências de uso do então, respeitando o critério metodológico de recolha dos dados de fala espontânea dos debatedores.

Elencamos, a seguir, as funcionalidades constatadas com base nas classificações e estudos realizados e citados anteriormente:

A) Operador argumentativo conclusivo

O então como operador argumentativo conclusivo é identificado, inicialmente, pela existência de enunciados argumentativos que são empregados com a intenção de orientar, no mesmo sentido, o interlocutor para certo tipo de conclusão. Esses argumentos constituem-se, portanto, uma classe argumentativa. Para a descrição desses enunciados, faz-se necessário determinar as direções/orientações possíveis provenientes de tais argumentos, ou melhor, determinar a orientação argumentativa (KOCH, 1987).

Nesse caso, identificamos três tipos de classes argumentativas e, como classificado, uma única orientação de argumentação, ou seja, a conclusiva. Desse modo, 
na sequência, apresentamos os "modelos" deste mesmo operador consoante suas classes, com exemplificações e explanações.

Padrão funcional 1: Dados estatísticos + ENTÃO (que retoma os dados e direciona à conclusão) + CONCLUSÃO

Os dados estatísticos, termos de quantificação aproximada ou dados de estudos científicos são empregados com o intuito de dar maior verossimilhança à argumentação formulada, bem como uma conclusão mais convincente, uma vez que, tomando tais dados como seus principais enunciados argumentativos, o debatedor utiliza-se de argumentos de autoridade, que são, em tese, verossímeis e que fazem o interlocutor e o ouvinte concluir da maneira como o primeiro debatedor deseja concluir, orientando, dessa forma, as considerações já refletidas e, claro, desejadas. Vemos tal mecanismo nos seguintes exemplos ${ }^{\mathrm{v}}$ :

(1) Debatedor $\mathrm{A}^{\mathrm{vi}}$ : apesar de a gente empreender uma GUErra contra o TRÁfico de drogas contra o tráfico de maconha éh:: a gente não reduziu o consumo e essa GUErra às drogas ela tem produzido um número enorme de homicídios né? (...) então... tá na hora de a gente reconhecer que a política de guerra às drogas é faLlda... e que a gente tem que (en)carar a problemática do consumo de drogas como problema de saúde... Pública (um) problema de liberdade individual (...)

(2) Debatedora A2: hoje a gente tem um problema MUito sério de saúde com as drogas Lícitas que elas são legalizadas como o álcool... e a maconha... nós temos a questão HOJE nós temos 120 MIL pessoas no Brasil que morrem acometidas por problemas com usos de álcool uma droga ABsolutamente legalizada Lícita... e nós temos aí eh:: uma população eNORme pela Organização Mundial de Saúde 400 mil pessoas que são acometidas por doenças vinculadas ao uso do taBAco... o que... nós sabemos é que a questão eh: hoje não há mais a criminalização da questão DO porte e DO usuário então não é isso que está em debate até porque nós avançamos nisso o que a gente percebe é que existe aí uma distorção dos Fatos e que na medida em que eu preservo essa 


questão do USO e do PORti eh:: com que critérios aonde que eu tô me baseando com
que critérios (...)
(3) Debatedora A2: (...) a partir da nova lei de drogas realmente você teve um... um
aumento do número de pessoas sendo:.: sendo:: pegas na rua e etc. teve uma um
endurecimento na aplicação da lei no início quando cê vai vê os números
principalmente a gente tem muitas pesquisas feitas em São Paulo no início lá em São
Paulo que você teve foi um aumento desproporcional das pessoas éh::: incriminadas
como traficantes e uma diminuição das pessoas incriminadas como... como... usuários
agora esse dado é do Rio de Janeiro em específico né(...) É isso tem que ser estudado
tem que descobrir quais esses fatores que levaram a isso. Se teve a gente tem um... um
processo de 2012 para cá de uma discussão maior na sociedade sobre esse assunto éh
um movimento de sensibilização do judiciário éh a defensoria pública do Rio de janeiro
começa a atuar mais nesses casos então pode ser que tenha aí uma... uma um bom
resultado dessa movimentação né.

Em ambos os fragmentos, as classes argumentativas são constituídas por dados estatísticos, factuais ou, em certos casos, por pesquisas e processos que possuem o mesmo escopo. Todos eles, por meio do item linguístico então, são anaforicamente retomados e orientados à conclusão planejada pelo debatedor, seja tal consideração final negativa ou positiva para o tópico discutido.

Padrão funcional 2: Raciocínio lógico: fatos restritivos (situações individualizadas) + ENTÃO + fatos generalizantes $=$ Conclusão OU fatos generalizantes + ENTÃO + fatos restritivos

(4) Debatedor B2: por outro lado como você sabe Jean éh::: essa coisa por exemplo na hora
que o menino tá viciado a tenDÊNcia dele é viciar o colega de escola pra que possa
daqui um pouco manter o seu próprio vício... então a hora que você vê uma situação
dessa aí eu te pergunto a quem interessa isso se por exemplo repito a associação
brasileira de psiquiatria diz que é isso e aí eu acredito na associação brasileira de
psiquiatria eles trazem dados por exemplo que aonde foi implantado isso não
funcionou se não funcionou trouxe muito mais traumas muito mais acidentes de
trânsito


(5) Debatedor B1: [ não eu num:: não concordo com esse ponto de vista até porque... não é o delegado de polícia não é o policial militar éh que define a aNÁlise no primeiro momento... da:: da da apreensão e hoje em dia nós temos que confiA na na nas nossas instituições o poder judiciário d... do Brasil éh: ... tem feito um papel éh:: ... fundamenTAL nós temos que a a acreditar na justiça até porque essa situações ela passa pelo crivo do ministério público $\mathrm{OU}$ da defensoria ou dum ad advogado quer dizer quem quem define isso é o ministério público então eu não posso imaginá que o ministério público em determinada situação ele é mais complacente porque é na Barra da Tijuca ou é na é na zona sul de São Paulo em detrimento do que acontece na zona norte...

Esta segunda classe argumentativa constitui-se de fatos, os quais ora podem ser restritivos (fatos individuais), ora amplos (gerais e com contexto mais abrangente) e que podem tanto ser classes, como também, parte da conclusão ou, nessas situações, a própria conclusão do enunciado.

Dessa forma, no fragmento (4), notamos uma exemplificação em que o vício de um determinado garoto é abordado para poder, a partir disso, orientar a argumentatividade do enunciado para a questão de interesse sobre a situação desenvolvida, ou melhor, quem se interessa sobre o vício de drogas, citando, posteriormente, uma organização governamental e alguns dados para complemento de sua conclusão, em detrimento de outras possíveis.

Já o (5) caracteriza o processo inverso, isto é, o debatedor utiliza-se, inicialmente, de uma personificação do conceito de justiça, com posterior citação de instituições responsáveis da área, para, assim, por meio do item então, orientar sua argumentação, bem como conclusão, à impossibilidade de incomplacência por parte de órgãos da Justiça sobre certos casos no Rio de Janeiro e em São Paulo.

Padrão funcional 3 - Assunto ou problema + ENTÃO + conclusão ou resolução 
Nesta última categoria, temos um típico método de argumentação: apresentar uma problemática ou determinado tema e, posteriormente, articular tal tese para uma específica conclusão ou resolução do problema.

(6) Debatedor A5: (...) nessa discussão do usuário do traficante a gente quer tiRA da esfera criminal as pessoas que fazem uso de drogas e tratá-las numa outra perspectiva seja aquelas sejam aquelas que têm problema com drogas e que então elas têm que ser cuidadas no âmbito da saúde da assistência social sejam aquelas...

(7) Debatedora A1: Olha foram pontos que a gente ouve o tempo inteiro né sendo levantados e que são questões reais eu acho que a gente tem que éh::: é eu acho que enfim entendendo a posição do Cid né? todo mundo tá aqui preocupado com qual é o acesso que o usuário tem a tratamento a gente quer saúde MAS a gente tem visões diferentes de como chegar até esse esse paradigma a Onu ah::: o escritório das Nações Unidas pra crimes transnacionais de drogas parte de um entendimento novo sobre o uso que ele tem que ser descriminalizado não era assim antes isso é uma nova posição onde exatamente por causa dessa dessa reflexão hoje em dia a criminalização ela traz um estigma que impede o acesso desse usuário a tratamento por causa de dois éh dois problemas o primeiro é o que eu expliquei antes o usuário éh::: se sente inibido pra chegar até ao serviço público e outro é o gasto público a gente tem ' $X$ ' de dinheiro e esse ' $X$ ' tem que então ser dividido entre medidas repressivas ou medidas éh:: ou programas de tratamento e atenção básica àqueles que têm problemas com drogas que fazem o uso problemático de drogas reformular como é feita essa divisão de ' $X$ ' é garantir que você tenha uma abordagem mais humana e a gente defende eficiente na política de drogas nacional

Em (6), observamos que o debatedor expõe, como tema, a dicotomia entre usuário e traficante, desse modo, problematiza-o com a questão criminalística do assunto e, orientado pelo então operador argumentativo conclusivo, soluciona a problemática com medidas que viabilizam um tratamento de saúde e de assistência social.

Já no fragmento (7), a debatedora apresenta sua tese a respeito do acesso ao tratamento de saúde por parte de um viciado. Por conseguinte, ela problematiza o tema com relações de causa-consequência, a saber: Criminalização do uso de drogas > gera um estigma > impede, por fim, acesso ao tratamento por parte do usuário. Com isso, há a 
orientação de suas ideias para uma resolução semelhante à do fragmento (6), a saber, o de buscar medidas para o tratamento destas pessoas no âmbito da saúde pública.

\section{B) Marcador conversacional}

Retomando Andrade (2011), o item então em sua pesquisa é caracterizado como marcador conversacional, não destacando, essencialmente, sua funcionalidade em correlação ao conteúdo do discurso, mas que possui relevância em seu aspecto interacional, pragmático e, consequentemente, argumentativo, cabendo, dessa forma, a seguir, breve explanação acerca desta funcionalidade.

Padrão funcional 4 - ENTÃO (posição à esquerda, encabeça sentença) + argumento

Encontramos uma característica frequente deste então em vários turnos discursivos dos debatedores que, de certa forma, necessitam do complemento de outro enunciador, por meio de perguntas e inferências que trazem contrapontos, além de se constituir, também, como um iniciador de turno que possui, superficialmente, um aspecto anafórico inerente ao item linguístico. Vejamos os exemplos a seguir:

(8) Mediador 5: embora ela [a maconha] abra portas para outras drogas?
Debatedora A5: ( ) Então quem abre a porta pra outras drogas é o tráfico de drogas (...)
(9) Mediador 6: [e isso vai demorar agora quanto tempo mais ou menos?
Debatedora B6: então... é difícil prever (o ministro) Farquim que é :: ahn o mi:ni:stro o
primeiro ministro que votou depois do relator ehh pediu vistas né o ministro Farquim
ahn:: recém ingresso no Supremo Tribunal Federal é o ministro:: ah que vem de área
civil ele é professor de direito civil então ele está:: ahn se inteirando a respeito do
assunto a expectativa é de que ele devol:va ah processo no dia trinta e um de agosto
né? a gente acredita que:: eh a ainda na primeira quinzena de setembro o Supremo
deve retomar a:: a votação


Nas exemplificações anteriores, tanto no fragmento (8) como no (9), observamos que o então como marcador conversacional possui aspecto anafórico, já que este retoma, subjetivamente, a pergunta feita - ora sobre a maconha ser uma "porta" para as demais drogas, ora sobre a duração de alguma problemática - por outro enunciador e, devido a isso, ao mesmo tempo, iniciar o turno discursivo do debatedor sobre o tópico proposto por seu interlocutor, não tendo, assim, um aspecto conclusivo como nas demais classificações.

Assim sendo, essa tipologia correlaciona-se ao aspecto de coesão na argumentação do debatedor, uma vez que interliga enunciados para asseverar a própria tese defendida.

\section{Considerações finais}

Apesar de não apresentarmos tipos de então com aspectos espaciais e/ou temporais, por ter realizado uma pesquisa sincrônica em corpus de modalidade oral, gênero debate regrado, é possível depreender que o então sofreu uma mudança linguística demonstrada no seguinte continuum: espaço > (tempo) > texto; assim sendo, originalmente, o então possuía um sentido espacial e, dado os contextos de uso, passa a ter a funcionalidade de articulador textual.

Com esta pesquisa, pudemos mapear e caracterizar as funcionalidades do elemento linguístico então como organizador textual, elencando dois tipos de usos: ora como um operador argumentativo conclusivo, o qual determina a orientação argumentativa do enunciador $(\mathrm{KOCH}, 1987)$, ora como marcador conversacional, o qual 
se constitui como um iniciador de turno que possui superficialmente um aspecto anafórico enunciativo.

Buscando responder às questões de pesquisa, voltemos a elas: (i) quanto à produtividade do uso do então em corpus de modalidade oral (debate), para além de categorizações, os dados permitem-nos caracterizar as diversas funções de orientação da fala ou da argumentação de um indivíduo que, muitas vezes, ultrapassa a escrita, como é caso do então anafórico, o qual caracteriza-se pelo aspecto pragmático e interacional como marcador conversacional, em relevância ao seu funcionamento formal como operador argumentativo. Já em (ii), os debates orais selecionados revelam que o uso do então é extremamente significativo (e necessário) para que haja correlação de ideias, fatos, estatísticas, possibilitando, por conseguinte, uma orientação argumentativa (por parte do debatedor) e uma orientação conclusiva evidenciada ao ouvinte sobre a perspectiva defendida.

Esta pesquisa ratifica o que já fora constatado em estudos com corpora compostos por textos escritos, contudo, contribui aos estudos linguísticos relacionados à gramaticalização e ao funcionalismo justamente por escolher ter, como foco, a oralidade e o discurso argumentativo e, acima de tudo, a funcionalidade do elemento linguístico pesquisado.

\section{Referências}

ANDRADE, M. L. C. V. de O. Língua: modalidade oral/escrita. In: UNIVERDADE ESTADUAL PAULISTA. Prograd. Caderno de formação: formação de professores didática geral. São Paulo: Cultura Acadêmica, 2011, p. 50-67, v. 11. 
CHIARELLI, G. A. A gramaticalização de então no português paulista: um estudo pancrônico. 139 f. Dissertação (Mestrado em Estudos Linguísticos) - Instituto de Biociências, Letras e Ciências Exatas, Universidade Estadual Paulista, São José do Rio Preto, 2011.

DIK, C. S. Funcional grammar. Cinnaminson - USA: Foris, 1978.

HEINE, B.; CLAUDI, U.; HÜNNEMEYER, F. Grammaticalization: a conceptual framework. Chicago: The University of Chicago Press. 1991.

HOPPER, P. J.; TRAUGOTT, E. C. Grammaticalization. Cambridge: Cambridge University Press. 1993.

HOUAISS, A. Dicionário eletrônico Houaiss da língua portuguesa. Rio de Janeiro: Objetiva. Versão 1.0 [CD-ROM]. 2001.

$\mathrm{KOCH}$, I. G. V. Uma visão argumentativa da gramática: os operadores argumentativos. In: KOCH, I. G. V. Argumentação e linguagem. São Paulo: Cortez, 1987. p. 105-110.

MARTELOTTA, M. E.; VOTRE, S. J.; CEZARIO, M. M. Gramaticalização no português do Brasil - uma abordagem funcional. UFRJ, Rio de Janeiro: 1996. Disponível em: <http://www.discursoegramatica.letras.ufrj.br/download/publicacao_livro_gramaticali zacao.pdf>. Acesso em: 06 maio 2016.

NEVES, M. H. de M. Uma visão geral da gramática funcional. ALFA: Revista de Linguística, v. 38, 1994.

A gramática: história, teoria e análise, ensino. São Paulo: Editora UNESP, 2002.

PRETI, Dino (org.). Oralidade em textos escritos. São Paulo: Editora Humanitas, 2009.

TRAUGOTT, E. C.; HEINE, B. Approaches to grammaticalization. Vol I. Focus on theoretical and methodological issues. Amsterdam: Benjamins, 1991.

Recebido em 3 de agosto de 2018.

Aceite em 4 de novembro de 2018.

\footnotetext{
' Resultado de projeto de Iniciação Científica/Bolsa Institucional - IFSP/Campus São Paulo, correspondente ao Edital no 256/2015; compõe os trabalhos do grupo de pesquisa/CNPq-IFSP - Descrição do Português do Brasil, na linha de pesquisa Estudos Analítico-descritivos da Linguagem.

ii Há vários estudos sincrônicos demonstrando itens em processo de gramaticalização, mas, normalmente, há a necessidade de um estudo pancrônico - isto é, uma análise conjunta dos aspectos sincrônicos e
} 
diacrônicos - para se ter um real panorama das mudanças linguísticas empreendidas por uma construção linguística como é o caso do operador argumentativo então.

iii Texto digital e sem numeração correspondente.

iv Utilizamos as normas de transcrição do Projeto NURC (Norma Urbana Culta), disponível em: <https://transcricoes.com.br/wp-content/uploads/.../Normas-transcrição-NURC.docx>.

"Todas as transcrições aqui expostas foram feitas conforme as "Normas para Transcrição", estabelecidas pelo projeto NURC/SP - Estudo da Norma Urbana Culta da Cidade de São Paulo - e organizadas por Preti (2009).

vi Os fragmentos transcritos estão com os nomes "debatedor" ou "debatedora", enumerados conforme a disposição dos enunciadores e, também, para preservação de suas identidades. 